\title{
Examining the Relationship between Heavy Alcohol Use and Assaults: With Adjustment for the Effects of Unmeasured Confounders
}

\author{
Wenbin Liang and Tanya Chikritzhs \\ National Drug Research Institute, Curtin University, P.O. Box U1987, Perth, WA 6845, Australia \\ Correspondence should be addressed to Wenbin Liang; w.liang@curtin.edu.au
}

Received 20 November 2014; Revised 12 March 2015; Accepted 16 March 2015

Academic Editor: Nana Kwame Anokye

Copyright (C) 2015 W. Liang and T. Chikritzhs. This is an open access article distributed under the Creative Commons Attribution License, which permits unrestricted use, distribution, and reproduction in any medium, provided the original work is properly cited.

Background. Experimental studies suggest that alcohol can lead to aggression in laboratory settings; however, it is impossible to test the causal relationship between alcohol use and real-life violence among humans in randomized clinical trials. Objectives. (i) To examine the relationship between heavy alcohol use and assaults in a population based study; (ii) to demonstrate the proxy outcome method, as a means of controlling the effects of unknown/unmeasured confounders in observational studies. Methods. This study used data collected from three waves of the National Survey on Drug Use and Health (NSDUH). The effects of heavy alcohol use on assault were measured using multivariable logistic regressions in conjunction with the proxy outcome method. Results. Application of the proxy outcome method indicated that effect sizes of heavy alcohol use on the risk of assault were overestimated in the standard models. After adjusting for the effects of unknown/unmeasured confounders, the risk of assault remained $43 \%$ and 63\% higher $(P<0.05)$ among participants who consumed 5+ drinks/day for 5-8 days/month and 9-30 days/month, respectively. Conclusions. Even after adjustment for unknown/unmeasured confounders the association between heavy alcohol use and risk of violence remained significant. These findings support the hypothesis that heavy alcohol use can cause violence.

\section{Introduction}

Substantial evidence from experimental studies suggests that alcohol can lead to aggression in laboratory settings [1-5] and validated laboratory methods to measure physical aggression such as the Taylor aggression paradigm [6] and the hot sauce procedure [7] have been well-developed. Nevertheless, it is difficult to generalize laboratory results to real-life occurrences of alcohol-related violence. It is impossible to test the causal relationship between alcohol use and physical violence that occurs among people in real life (such as assault) in randomized clinical trials due to ethical concerns. Data from observational studies have shown a positive association between alcohol use and violence in general populations. However, due to the nature of observational studies, it is difficult to conclude whether the observed association between alcohol use and violence is due to alcohol use or whether it is due to common cause factors [8-12]. For example, the well-designed longitudinal study by Fergusson and Horwood showed that cohort participants who had been diagnosed with alcohol abuse were more likely to be involved in violence and property crime. However, use of the data from their study alone was unable to determine whether alcohol caused the law-breaking behaviors or whether violence, property crime, and alcohol abuse were caused by common factors, for example, changes in mental health which may increase the likelihood of high-risk behaviors [13-16]. Therefore, further studies are required to test the hypothesis that heavy alcohol use causes violence.

Recent published works have demonstrated that unmeasured/unknown confounding effects could be estimated by measuring the association between the exposure variable (heavy alcohol use in this case) and a proxy outcome, on which the exposure has no or very limited effect [17-20]. The proxy outcome method is a general approach which provides estimates and adjustments for effects of unmeasured confounders. Many types of physical and mental health outcomes are affected by clusters of socioeconomic determinants 


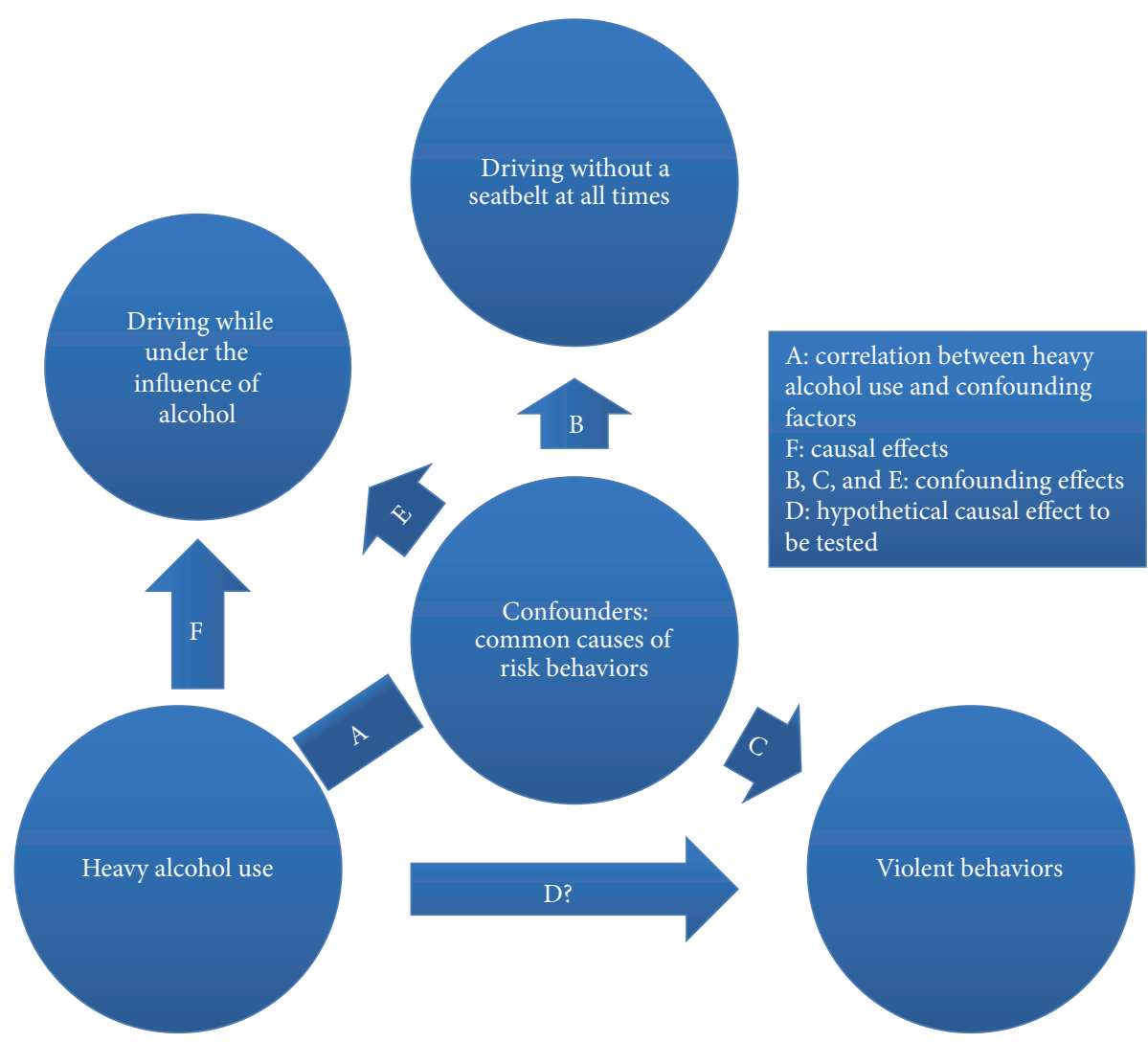

FIGURE 1: Illustration of an alternative approach to dealing with confounding effects.

and genetic and behavioural psychological factors [21-31]. Field specific knowledge and experience can be applied to determine the best proxy outcome for estimating effects of such unmeasured confounders. The papers by Tchetgen Tchetgen and Liang et al. provided detailed discussion on the methodological framework of the proxy outcome method $[17,19]$. A recent study by Liang and Chikritzhs applied the proxy outcome method to an investigation of the effect of alcohol use on health status. They used the health status of drinkers' children as the proxy outcome to measure and control for unknown/unmeasured confounding effects that cluster within families such as socioeconomic determinants, environmental factors, lifestyle, and genetic susceptibility [18]. The findings from this study concurred with the results from a lately published Mendelian randomization analysis of pooled data from prospective studies that measured genetic variants [32]: both studies suggested no protective effect of moderate alcohol use on health.

In the current study, the proxy outcome method was adopted to control the effects of unknown confounders. The criteria for a proxy outcome are (i) the exposure of interest is not a cause for the proxy outcome and (ii) causes of the proxy outcome and the main outcome are subsets of a pool of correlated variables [17]. In order to avoid overadjustment, a positive outcome was used. The criteria for a positive outcome are (i) the exposure of interest is a cause for the positive outcome and (ii) causes of the positive outcome, the proxy outcome, and the main outcome are subsets of a pool of correlated variables. In relation to this study, driving without a seatbelt at all times met the criteria of a proxy outcome, and driving while under the influence of alcohol met the criteria of a positive outcome since (i) the three outcomes (violent behavior, driving without a seatbelt at all times, and driving while under the influence of alcohol) are all risktaking illegal behaviors which share a set of similar social, environmental, and genetic risk factors [15, 33-35], as well as a similar direction and magnitude of response bias due to social desirability [36], and (ii) heavy alcohol use has minimum effect on driving without a seatbelt at all times while heavy alcohol use is an important cause of drink-driving (but not an essential cause, as some cases may be due to "moderate" level drinking) (also see Figure 1).

\section{Materials and Methods}

This study used data collected from three waves (2009, 2010, and 2011) of the National Survey on Drug Use and Health (NSDUH). NSDUH surveys are conducted to measure the prevalence and correlates of drug use in the United States. Details of the survey method have been described previously [37-39]. Briefly, NSDUH surveys are multistage national surveys with representative samples of noninstitutionalized population of the United States aged 12 years or older. In-home, computer-assisted interviews were used to collect the data. Since 2002, each participant who completed the survey was provided a $\$ 30$ cash payment to improve 
TABLE 1: Associations between heavy alcohol use and three outcome variables (violent behaviour, driving without wearing a seatbelt all of the time, and driving under the influence of alcohol). Estimates from standard logistic regression.

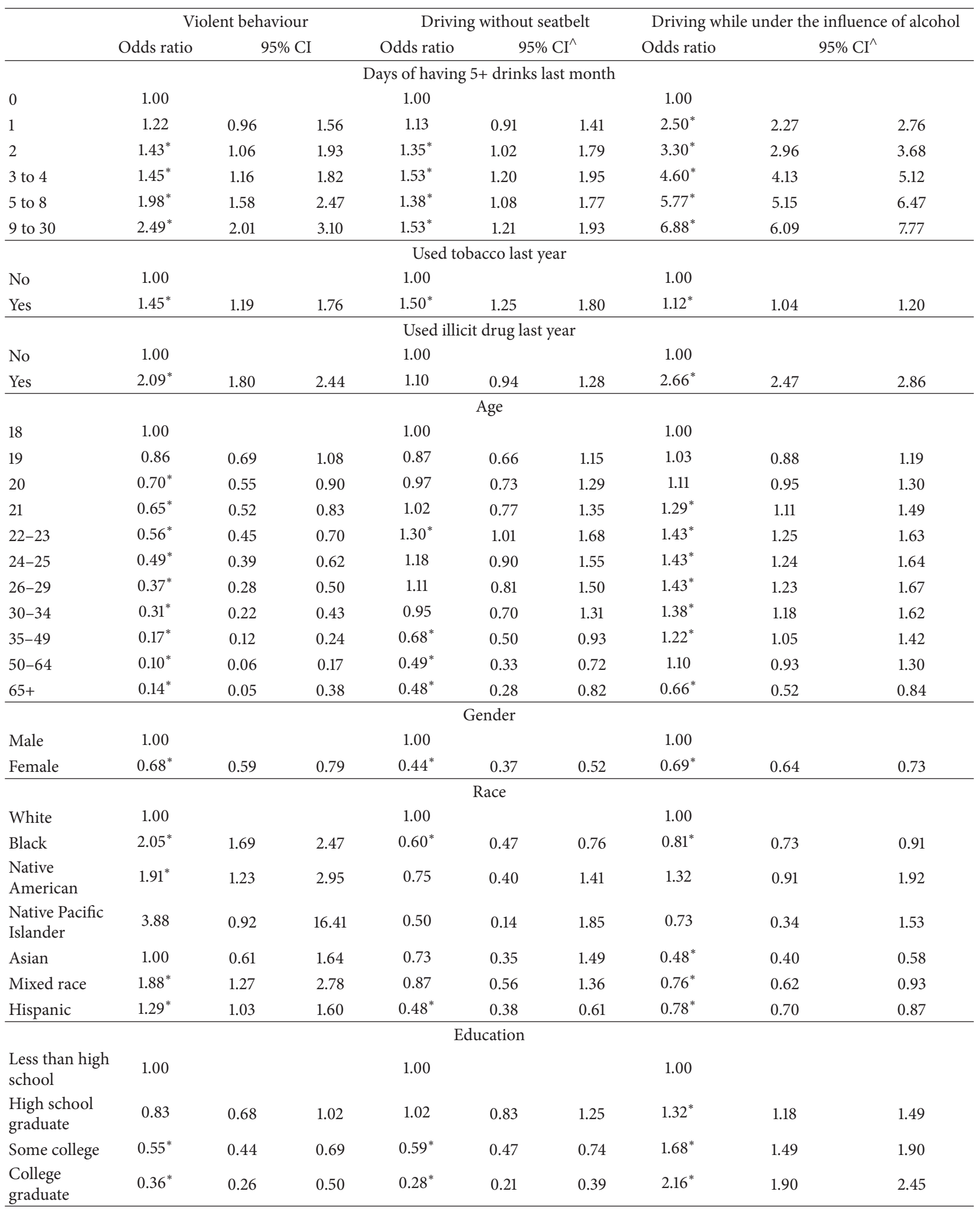


TABle 1: Continued.

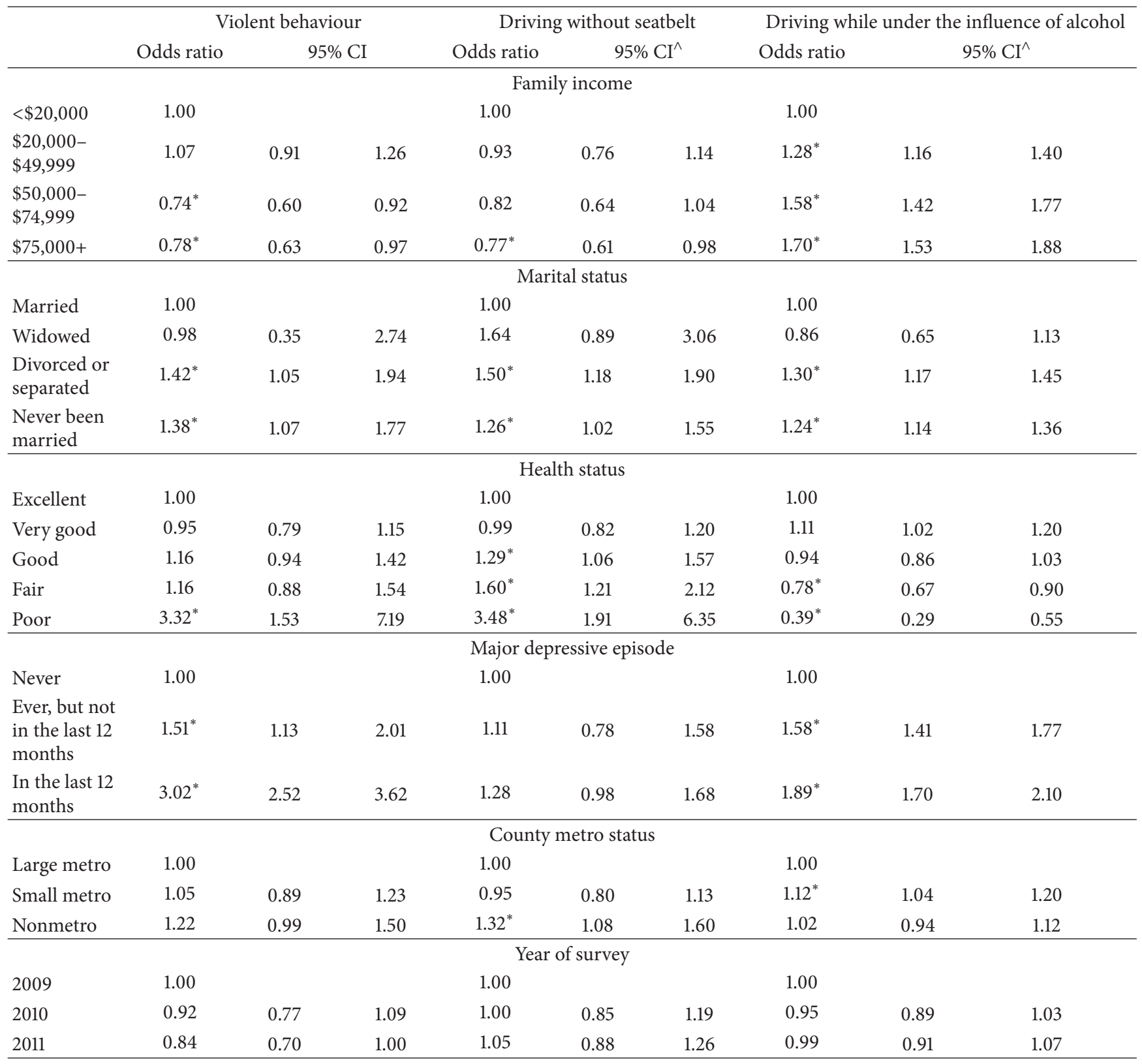

$\wedge 95 \%$ confidence interval.

${ }^{*} P<0.05$.

the response rate. The response rates were $75.7 \%, 74.7 \%$, and $74.4 \%$ for the 2009,2010 , and 2011 survey, respectively [3739]. In addition to the questions on demographics and use of tobacco products, alcohol, and illicit drugs, participants were also asked questions about risk behaviors in the past 12 months and questions that assess mental and physical health conditions. This study included the samples from the 2009, 2010 , and 2011 NSDUH surveys who were 18 years or older at the time of the survey, had consumed alcohol, and drove a car in the past 12 months.

Responses to the following questions were used to define violence, driving without seatbelt, and driving under the influence of alcohol: (1) violent behavior: "During the past 12 months, how many times have you attacked someone with the intent to seriously hurt them?"; (2) driving without seatbelt: "How often do you wear a seatbelt when you drive a car?"; and (3) driving under the influence of alcohol: "During the past 12 months, have you driven a vehicle while you were under the influence of alcohol?". Answers to these questions were converted to three corresponding binary variables (yes/no) to represent the presence/absence of violent behavior (i.e., a yes if ever tried to seriously hurt someone in the past 12 months), driving without seatbelt at all times (yes if never wore a seatbelt when driving in the past 12 months), and driving under the influence of alcohol (yes if ever drove under the influence of alcohol in the past 12 months), respectively. 
TABLE 2: Associations between heavy alcohol use and two outcome variables (assault and driving under the influence of alcohol). Estimates from standard logistic regression plus additional control for the effects of unmeasured confounders.

\begin{tabular}{|c|c|c|c|c|c|c|}
\hline & \multicolumn{3}{|c|}{ Violent behaviour } & \multicolumn{3}{|c|}{ Driving while under the influence of alcohol } \\
\hline & Odds ratio & \multicolumn{2}{|c|}{$95 \% \mathrm{CI}^{\wedge}$} & Odds ratio & & $95 \% \mathrm{CI}^{\wedge}$ \\
\hline \multicolumn{7}{|c|}{ Days of having $5+$ drinks last month } \\
\hline 0 & 1.00 & & & 1.00 & & \\
\hline 1 & 1.08 & 0.85 & 1.38 & $2.22^{*}$ & 2.01 & 2.44 \\
\hline 2 & 1.06 & 0.78 & 1.43 & $2.44^{*}$ & 2.19 & 2.72 \\
\hline 3 to 4 & 0.95 & 0.76 & 1.19 & $3.01^{*}$ & 2.70 & 3.35 \\
\hline 5 to 8 & $1.43^{*}$ & 1.15 & 1.79 & $4.18^{*}$ & 3.73 & 4.69 \\
\hline 9 to 30 & $1.63^{*}$ & 1.31 & 2.03 & $4.50^{*}$ & 3.99 & 5.08 \\
\hline
\end{tabular}

Model controlled for the same potential confounding factors listed in Table 1 plus additional control for the effects of unmeasured confounders derived from proxy models.

$\wedge 95 \%$ confidence interval.

${ }^{*} P<0.05$.

TABLE 3: Comparison of estimates derived from standard univariate models and estimates derived from univariate models with proxy outcome method alone to account for all confounding effects.

\begin{tabular}{|c|c|c|c|c|c|c|c|c|c|}
\hline & \multicolumn{3}{|c|}{ Violent behaviour } & \multicolumn{3}{|c|}{ Driving without seatbelt } & \multicolumn{3}{|c|}{ Driving while under the influence of alcohol } \\
\hline & Odds ratio & \multicolumn{2}{|c|}{$95 \% \mathrm{CI}$} & Odds ratio & & $95 \% \mathrm{CI}$ & Odds ratio & & $95 \% \mathrm{CI}^{\wedge}$ \\
\hline \multicolumn{10}{|c|}{ Estimates from univariate models } \\
\hline \multicolumn{10}{|c|}{ Days of having $5+$ drinks last month } \\
\hline 0 & 1.00 & & & 1.00 & & & 1.00 & & \\
\hline 1 & $1.99^{*}$ & 1.57 & 2.52 & $1.57^{*}$ & 1.25 & 1.96 & $2.94^{*}$ & 2.68 & 3.21 \\
\hline 2 & $2.73^{*}$ & 2.09 & 3.56 & $2.14^{*}$ & 1.64 & 2.79 & $4.02^{*}$ & 3.64 & 4.44 \\
\hline 3 to 4 & $3.17^{*}$ & 2.57 & 3.91 & $2.68^{*}$ & 2.14 & 3.35 & $6.01^{*}$ & 5.46 & 6.62 \\
\hline 5 to 8 & $4.62^{*}$ & 3.75 & 5.70 & $2.64^{*}$ & 2.08 & 3.36 & $8.31^{*}$ & 7.51 & 9.19 \\
\hline 9 to 30 & $6.53^{*}$ & 5.38 & 7.94 & $3.55^{*}$ & 2.87 & 4.39 & $10.20^{*}$ & 9.17 & 11.34 \\
\hline
\end{tabular}

Estimates from univariate models with proxy outcome method

Days of having $5+$ drinks last month

\begin{tabular}{llllllll}
0 & 1.00 & & & 1.00 & & \\
1 & 1.27 & 1.00 & 1.61 & & $1.88^{*}$ & 1.71 & 2.05 \\
2 & 1.27 & 0.98 & 1.66 & Estimates not applicable for proxy outcome & $1.88^{*}$ & 1.70 & 2.07 \\
3 to 4 & 1.18 & 0.96 & 1.46 & (will always be equal to 1) & $2.25^{*}$ & 2.04 & 2.47 \\
5 to 8 & $1.75^{*}$ & 1.42 & 2.15 & $3.14^{*}$ & 2.84 & 3.47 \\
9 to 30 & $1.84^{*}$ & 1.52 & 2.24 & $2.87^{*}$ & 2.58 & 3.20 \\
\hline
\end{tabular}

$\wedge_{95 \% \text { confidence interval. }}$

${ }^{*} P<0.05$.

NSDUH survey referred a "drink" as a "can or bottle of beer, or a wine cooler, a shot of liquor, or a mixed drink with liquor in it" [37-39]. Number of days in which five or more drinks were consumed on the same occasion (occasion: "at the same time or within a couple of hours") in the past 30 days prior to the interview was used as the measurement of heavy alcohol use. Number of days when consuming $5+$ drinks over the past 30 days was converted into a six-category variable: 0 days, 1 day, 2 days, 3-4 days, 5-8 days, and 9-30 days. These cutoff points were chosen to ensure that while having as many categories as possible, the smallest sample size of a category was at least $5 \%$ of the total sample.

Multivariable logistic regressions were used to examine the relationships between the outcome variables (assault, driving without wearing seatbelt all of the time, and driving under the influence of alcohol) and heavy alcohol use while controlling for demographics (age, gender, race, marital status, and type of country of living); socioeconomic status (income and highest academic achievement); health (general health status). Whether ever had a lifetime major depressive episode, and if yes then whether there was an episode in the past 12 months which was assessed based on criteria in the Diagnostic and Statistical Manual of Mental Disorders 4th Edition (DSM-IV); and use of tobacco or any illicit drug in the past 12 months. The association between driving without wearing seatbelt and heavy alcohol use was used as a proxy estimate of unknown confounding effects toward the relationship between violence and heavy alcohol use as well as the relationship between driving under the influence of alcohol and heavy alcohol use. A final regression model 
TABLE 4: Descriptive frequency statistics for violent behaviours, alcohol use, and controlled potential confounders.

\begin{tabular}{|c|c|c|c|}
\hline & \multicolumn{3}{|c|}{ Violent behaviour } \\
\hline & Yes & No & Total \\
\hline \multicolumn{4}{|c|}{ Days of having $5+$ drinks last month } \\
\hline 0 & 45,069 & 842 & 45,911 \\
\hline 1 & 10,356 & 293 & 10,649 \\
\hline 2 & 7,102 & 306 & 7,408 \\
\hline 3 to 4 & 6,800 & 334 & 7,134 \\
\hline 5 to 8 & 5,672 & 341 & 6,013 \\
\hline 9 to 30 & 4,693 & 464 & 5,157 \\
\hline \multicolumn{4}{|c|}{ Used tobacco last year } \\
\hline No & 40,005 & 571 & 40,576 \\
\hline Yes & 39,687 & 2,009 & 41,696 \\
\hline \multicolumn{4}{|c|}{ Used illicit drug last year } \\
\hline No & 56,921 & 946 & 57,867 \\
\hline Yes & 22,771 & 1,634 & 24,405 \\
\hline \multicolumn{4}{|c|}{ Age } \\
\hline 18 & 4,144 & 395 & 4,539 \\
\hline 19 & 4,374 & 322 & 4,696 \\
\hline 20 & 4,689 & 268 & 4,957 \\
\hline 21 & 5,419 & 311 & 5,730 \\
\hline $22-23$ & 10,500 & 460 & 10,960 \\
\hline $24-25$ & 10,367 & 354 & 10,721 \\
\hline $26-29$ & 6,046 & 152 & 6,198 \\
\hline $30-34$ & 6,601 & 127 & 6,728 \\
\hline $35-49$ & 17,165 & 155 & 17,320 \\
\hline $50-64$ & 7,234 & 27 & 7,261 \\
\hline $65+$ & 3,153 & 9 & 3,162 \\
\hline \multicolumn{4}{|c|}{ Gender } \\
\hline Male & 38,700 & 1,608 & 40,308 \\
\hline Female & 40,992 & 972 & 41,964 \\
\hline \multicolumn{4}{|c|}{ Race } \\
\hline White & 54,968 & 1,392 & 56,360 \\
\hline Black & 8,197 & 508 & 8,705 \\
\hline Native American & 1,020 & 78 & 1,098 \\
\hline Native Pacific Islander & 313 & 18 & 331 \\
\hline Asian & 2,525 & 43 & 2,568 \\
\hline Mixed race & 2,253 & 129 & 2,382 \\
\hline Hispanic & 10,416 & 412 & 10,828 \\
\hline \multicolumn{4}{|c|}{ Education } \\
\hline Less than high school & 9,125 & 663 & 9,788 \\
\hline High school graduate & 24,301 & 1,096 & 25,397 \\
\hline Some college & 25,729 & 659 & 26,388 \\
\hline College graduate & 20,537 & 162 & 20,699 \\
\hline \multicolumn{4}{|c|}{ Family income } \\
\hline$<\$ 20,000$ & 17,994 & 881 & 18,875 \\
\hline$\$ 20,000-\$ 49,999$ & 26,213 & 978 & 27,191 \\
\hline$\$ 50,000-\$ 74,999$ & 13,366 & 321 & 13,687 \\
\hline$\$ 75,000+$ & 22,119 & 400 & 22,519 \\
\hline
\end{tabular}

TABLE 4: Continued.

\begin{tabular}{|c|c|c|c|}
\hline & \multicolumn{3}{|c|}{ Violent behaviour } \\
\hline & Yes & No & Total \\
\hline \multicolumn{4}{|c|}{ Marital status } \\
\hline Married & 28,638 & 289 & 28,927 \\
\hline Widowed & 1,266 & 11 & 1,277 \\
\hline Divorced or separated & 7,376 & 187 & 7,563 \\
\hline Never been married & 42,412 & 2,093 & 44,505 \\
\hline \multicolumn{4}{|c|}{ Health status } \\
\hline Excellent & 21,488 & 557 & 22,045 \\
\hline Very good & 32,969 & 980 & 33,949 \\
\hline Good & 19,481 & 762 & 20,243 \\
\hline Fair & 4,971 & 243 & 5,214 \\
\hline Poor & 783 & 38 & 821 \\
\hline \multicolumn{4}{|c|}{ Major depressive episode } \\
\hline Never & 67,989 & 1,908 & 69,897 \\
\hline Ever, but not in the last 12 months & 5,450 & 176 & 5,626 \\
\hline In the last 12 months & 6,253 & 496 & 6,749 \\
\hline \multicolumn{4}{|c|}{ County metro status } \\
\hline Large metro & 34,746 & 1,052 & 35,798 \\
\hline Small metro & 28,703 & 968 & 29,671 \\
\hline Nonmetro & 16,243 & 560 & 16,803 \\
\hline \multicolumn{4}{|c|}{ Year of survey } \\
\hline 2009 & 26,084 & 929 & 27,013 \\
\hline 2010 & 27,080 & 872 & 27,952 \\
\hline 2011 & 26,528 & 779 & 27,307 \\
\hline
\end{tabular}

was then performed to obtain the new estimates for violence and alcohol use that controlled for the confounding effects estimated by the proxy models. STATA 12 developed by StataCorp was used to perform the analysis. For further illustration, additional logistic regression models were fitted with only alcohol use as a predictor variable-treating all potential confounding factors as unknown (i.e., factors shown in Table 1, such as age, gender, and race) and leaving all confounding effects for the proxy outcome to account for.

There were 82,790 participants that met the selection criteria. Less than $1 \%$ of these participants did not provide necessary information on the dependent variables or some of the independent variables and therefore were excluded from the analysis ( $n=82,272$ remained in the analysis). The sampling weight supplied with the dataset was used in all analyses [37].

\section{Results}

Multivariable analysis showed that all of the three outcomes were significantly associated with heavy alcohol use after controlling for a number of known potential confounders (Table 1). The descriptive statistics are showed in Tables 4 , 5 , and 6 . The effect size of heavy alcohol use was largest on driving under the influence of alcohol, which is known to be at least partly caused by heavy use (i.e., moderate levels of alcohol use may also be a cause of positive responses for driving under the influence of alcohol). The effect size of 
TABLE 5: Descriptive frequency statistics for driving without seatbelt, alcohol use and controlled potential confounders.

\begin{tabular}{|c|c|c|c|}
\hline & \multicolumn{3}{|c|}{ Driving without seatbelt } \\
\hline & No & Yes & Total \\
\hline \multicolumn{4}{|c|}{ Days had 5+ drinks last month } \\
\hline 0 & 44,888 & 1,023 & 45,911 \\
\hline 1 & 10,308 & 341 & 10,649 \\
\hline 2 & 7,092 & 316 & 7,408 \\
\hline 3 to 4 & 6,786 & 348 & 7,134 \\
\hline 5 to 8 & 5,691 & 322 & 6,013 \\
\hline 9 to 30 & 4,792 & 365 & 5,157 \\
\hline \multicolumn{4}{|c|}{ Used tobacco last year } \\
\hline No & 39,911 & 665 & 40,576 \\
\hline Yes & 39,646 & 2,050 & 41,696 \\
\hline \multicolumn{4}{|c|}{ Used illicit drug last year } \\
\hline No & 56,381 & 1,486 & 57,867 \\
\hline Yes & 23,176 & 1,229 & 24,405 \\
\hline \multicolumn{4}{|c|}{ Age } \\
\hline 18 & 4,314 & 225 & 4,539 \\
\hline 19 & 4,474 & 222 & 4,696 \\
\hline 20 & 4,741 & 216 & 4,957 \\
\hline 21 & 5,481 & 249 & 5,730 \\
\hline $22-23$ & 10,490 & 470 & 10,960 \\
\hline $24-25$ & 10,297 & 424 & 10,721 \\
\hline $26-29$ & 5,987 & 211 & 6,198 \\
\hline $30-34$ & 6,561 & 167 & 6,728 \\
\hline $35-49$ & 16,950 & 370 & 17,320 \\
\hline $50-64$ & 7,143 & 118 & 7,261 \\
\hline $65+$ & 3,119 & 43 & 3,162 \\
\hline \multicolumn{4}{|c|}{ Gender } \\
\hline Male & 38,425 & 1,883 & 40,308 \\
\hline Female & 41,132 & 832 & 41,964 \\
\hline \multicolumn{4}{|c|}{ Race } \\
\hline White & 54,303 & 2,057 & 56,360 \\
\hline Black & 8,474 & 231 & 8,705 \\
\hline Native American & 1,056 & 42 & 1,098 \\
\hline Native Pacific Islander & 325 & 6 & 331 \\
\hline Asian & 2,539 & 29 & 2,568 \\
\hline Mixed race & 2,294 & 88 & 2,382 \\
\hline Hispanic & 10,566 & 262 & 10,828 \\
\hline \multicolumn{4}{|c|}{ Education } \\
\hline Less than high school & 9,169 & 619 & 9,788 \\
\hline High school graduate & 24,181 & 1,216 & 25,397 \\
\hline Some college & 25,696 & 692 & 26,388 \\
\hline College graduate & 20,511 & 188 & 20,699 \\
\hline \multicolumn{4}{|c|}{ Family income } \\
\hline$<\$ 20,000$ & 18,159 & 716 & 18,875 \\
\hline$\$ 20,000-\$ 49,999$ & 26,110 & 1,081 & 27,191 \\
\hline$\$ 50,000-\$ 74,999$ & 13,286 & 401 & 13,687 \\
\hline$\$ 75,000+$ & 22,002 & 517 & 22,519 \\
\hline
\end{tabular}

TABLE 5: Continued.

\begin{tabular}{lccc}
\hline \multicolumn{4}{c}{ Driving without seatbelt } \\
& No & Yes & Total \\
\hline \multirow{4}{*}{ Marital status } & \\
Widowed & 28,363 & 564 & 28,927 \\
Divorced or separated & 1,248 & 29 & 1,277 \\
Never been married & 7,273 & 290 & 7,563 \\
\hline \multicolumn{4}{c}{ Health status } \\
Excellent & 21,479 & 566 & 22,045 \\
Very good & 33,005 & 944 & 33,949 \\
Good & 19,356 & 887 & 20,243 \\
Fair & 4,958 & 256 & 5,214 \\
Poor & 759 & 62 & 821 \\
\hline \multicolumn{4}{c}{ Major depressive episode } \\
Never & 67,589 & 2,308 & 69,505 \\
Ever, but not in the last 12 months & 5,483 & 143 & 5,697 \\
In the last 12 months & 6,485 & 264 & 6,749 \\
\hline \multicolumn{4}{c}{ County metro status } \\
Large metro & 34,873 & 925 & 35,798 \\
Small metro & 28,748 & 923 & 29,671 \\
Nonmetro & 15,936 & 867 & 16,803 \\
\hline \multicolumn{4}{c}{ Year of survey } \\
2009 & 26,083 & 930 & 27,013 \\
2010 & 27,049 & 903 & 27,952 \\
& 26,425 & 882 & 27,307 \\
\hline
\end{tabular}

heavy alcohol use on violence was the second largest. The effect of heavy alcohol use on driving without a seatbelt at all times was smallest but remained significant. This provided a useful indicator of the magnitude of unknown/unmeasured confounding effects on the association between alcohol use and violent behavior.

The natural logarithms of the adjusted odds ratio for driving without a seatbelt by number of days with heavy alcohol use in the last 30 days were 0 (reference level) for 0 days, 0.12 for 1 day, 0.30 for 2 days, 0.42 for 3-4 days, 0.32 for 5-8 days, and 0.42 for 9 days or more, respectively. After offsetting the residual confounding effects, the effect of heavy alcohol use on violence became nonsignificant for 4 days' or less exposure in the last 30 days. Although reduced, the effects of 5-8 days' and 9+ days' heavy alcohol use on the risk of violence nevertheless remained significant. The estimates for the effects of heavy alcohol use on driving under the influence of alcohol were reduced but remained significant for all exposure categories (Table 2).

\section{Discussion}

This study examined the association between heavy alcohol use and risk of violence in uncontrolled settings (i.e., observational rather than experimental). The proxy outcome approach was employed to account for unknown/unmeasured confounding effects that may remain in estimates obtained using the standard approach. In both the standard 
TABLE 6: Descriptive frequency statistics for driving while under the influence of alcohol, alcohol use and controlled potential confounders.

\begin{tabular}{|c|c|c|c|}
\hline & \multicolumn{3}{|c|}{$\begin{array}{l}\text { Driving while under the } \\
\text { influence of alcohol }\end{array}$} \\
\hline & No & Yes & Total \\
\hline \multicolumn{4}{|c|}{ Days had $5+$ drinks last month } \\
\hline 0 & 40,715 & 5,196 & 45,911 \\
\hline 1 & 8,010 & 2,639 & 10,649 \\
\hline 2 & 5,026 & 2,382 & 7,408 \\
\hline 3 to 4 & 4,271 & 2,863 & 7,134 \\
\hline 5 to 8 & 3,079 & 2,934 & 6,013 \\
\hline 9 to 30 & 2,188 & 2,969 & 5,157 \\
\hline \multicolumn{4}{|c|}{ Used tobacco last year } \\
\hline No & 34,317 & 6,259 & 40,576 \\
\hline Yes & 28,972 & 12,724 & 41,696 \\
\hline \multicolumn{4}{|c|}{ Used illicit drug last year } \\
\hline No & 48,963 & 8,904 & 57,867 \\
\hline Yes & 14,326 & 10,079 & 24,405 \\
\hline \multicolumn{4}{|c|}{ Age } \\
\hline 18 & 3,544 & 995 & 4,539 \\
\hline 19 & 3,518 & 1,178 & 4,696 \\
\hline 20 & 3,698 & 1,259 & 4,957 \\
\hline 21 & 4,092 & 1,638 & 5,730 \\
\hline $22-23$ & 7,717 & 3,243 & 10,960 \\
\hline $24-25$ & 7,664 & 3,057 & 10,721 \\
\hline $26-29$ & 4,587 & 1,611 & 6,198 \\
\hline $30-34$ & 5,199 & 1,529 & 6,728 \\
\hline $35-49$ & 14,100 & 3,220 & 17,320 \\
\hline $50-64$ & 6,212 & 1,049 & 7,261 \\
\hline $65+$ & 2,958 & 204 & 3,162 \\
\hline \multicolumn{4}{|c|}{ Gender } \\
\hline Male & 29,239 & 11,069 & 40,308 \\
\hline Female & 34,050 & 7,914 & 41,964 \\
\hline \multicolumn{4}{|c|}{ Race } \\
\hline White & 42,468 & 13,892 & 56,360 \\
\hline Black & 7,149 & 1,556 & 8,705 \\
\hline Native American & 814 & 284 & 1,098 \\
\hline Native Pacific Islander & 255 & 76 & 331 \\
\hline Asian & 2,131 & 437 & 2,568 \\
\hline Mixed race & 1,811 & 571 & 2,382 \\
\hline Hispanic & 8,661 & 2,167 & 10,828 \\
\hline \multicolumn{4}{|c|}{ Education } \\
\hline Less than high school & 8,019 & 1,769 & 9,788 \\
\hline High school graduate & 20,081 & 5,316 & 25,397 \\
\hline Some college & 19,756 & 6,632 & 26,388 \\
\hline College graduate & 15,433 & 5,266 & 20,699 \\
\hline \multicolumn{4}{|c|}{ Family income } \\
\hline$<\$ 20,000$ & 14,557 & 4,318 & 18,875 \\
\hline$\$ 20,000-\$ 49,999$ & 21,107 & 6,084 & 27,191 \\
\hline$\$ 50,000-\$ 74,999$ & 10,530 & 3,157 & 13,687 \\
\hline$\$ 75,000+$ & 17,095 & 5,424 & 22,519 \\
\hline
\end{tabular}

TABle 6: Continued.

\begin{tabular}{|c|c|c|c|}
\hline & \multicolumn{3}{|c|}{$\begin{array}{l}\text { Driving while under the } \\
\text { influence of alcohol }\end{array}$} \\
\hline & No & Yes & Total \\
\hline \multicolumn{4}{|c|}{ Marital status } \\
\hline Married & 24,193 & 4,734 & 28,927 \\
\hline Widowed & 1,157 & 120 & 1,277 \\
\hline Divorced or separated & 5,994 & 1,569 & 7,563 \\
\hline Never been married & 31,945 & 12,560 & 44,505 \\
\hline \multicolumn{4}{|c|}{ Health status } \\
\hline Excellent & 17,083 & 4,962 & 22,045 \\
\hline Very good & 25,544 & 8,405 & 33,949 \\
\hline Good & 15,670 & 4,573 & 20,243 \\
\hline Fair & 4,277 & 937 & 5,214 \\
\hline Poor & 715 & 106 & 821 \\
\hline \multicolumn{4}{|c|}{ Major depressive episode } \\
\hline Never & 54,700 & 15,197 & 69,897 \\
\hline $\begin{array}{l}\text { Ever, but not in the } \\
\text { last } 12 \text { months }\end{array}$ & 4,029 & 1,597 & 5,626 \\
\hline In the last 12 months & 4,560 & 2,189 & 6,749 \\
\hline \multicolumn{4}{|c|}{ County metro status } \\
\hline Large metro & 27,777 & 8,021 & 35,798 \\
\hline Small metro & 22,535 & 7,136 & 29,671 \\
\hline Nonmetro & 12,977 & 3,826 & 16,803 \\
\hline \multicolumn{4}{|c|}{ Year of survey } \\
\hline 2009 & 20,449 & 6,564 & 27,013 \\
\hline 2010 & 21,565 & 6,387 & 27,952 \\
\hline 2011 & 21,275 & 6,032 & 27,307 \\
\hline
\end{tabular}

and proxy outcome approaches it was observed that heavy alcohol use for 5 days or more in the past 30 days was significantly associated with increased risk of violence. This observation is consistent with findings from experimental studies which suggest that alcohol use may increase aggression in both humans and animals [1, 2, 40-42]. It has been hypothesized that physiological effects of alcohol on the central nervous system can impair cognitive functions that regulate emotion and behaviors [43, 44]. Individuals who have been suppressing angry feelings may express anger through acts of physical violence when self-control mechanisms are compromised due to alcohol use [11, 43-45].

The proxy outcome used in this study was driving without wearing a seatbelt at all times. Since not wearing a seatbelt at all times is not caused by alcohol, the apparent association is due to confounding. Similar confounding likely affected the apparent association between heavy alcohol use and violent behavior. Therefore, by controlling for confounding identified in the proxy outcome, we have more accurately described the magnitude of the true association between alcohol and violence. Thus, using a novel approach, this study has provided further evidence to support the notion that there is a causal relationship between alcohol use and violence.

We have described here an alternative approach to dealing with unknown/unmeasured confounding factors in 
observational studies that has application to the wider field of epidemiology. To further illustrate the application of this approach, we ran additional logistic regression models that were fitted with alcohol use as the only predictor (univariate model), thereby creating a hypothetical scenario where all potential confounding factors were unknown. We then applied the proxy outcome method as the only means of adjusting for potential confounding effects. As the estimates in Table 3 indicated, the confounding which dominated the crude results had been significantly removed using only the proxy outcome method and these estimates were, in fact, closely comparable to estimates derived using the standard approach that controlled for all known potential confounding factors (Table 1). Figure 1 was presented to further explain this approach. In order to measure " $\mathrm{D}$ " and " $\mathrm{F}$ " while adjusting for confounding, the effect size of " $\mathrm{B}$ " was used as approximation of the effect sizes of "C" and "E." The certain causal effect of heavy alcohol use on driving under the influence of alcohol denoted as "F" was used as a positive control to detect whether any overadjustment had occurred.

The proxy outcome method is a general approach that enables analysts to control for the effects of unknown/ unmeasured confounding factors. The advantage of this approach is that it will tend toward producing more conservative outcomes (i.e., effect sizes) than the standard approach which assumes that unknown/unmeasured confounding is minimal. However, under some circumstances, where the effect size of unmeasured confounding effects is severely overestimated, it may make a true causal effect (if it exists) undetectable. Therefore, a positive control outcome, such as the driving under the influence of alcohol variable used in this study, may be used to detect whether any overadjustment has occurred. In this case, after further adjustment, the effects of alcohol on the positive outcome remained significant at all levels of heavy alcohol use and therefore indicative that the true effect of alcohol exposure on violence is likely to remain detectable.

\section{Conclusion}

The association between heavy alcohol use and risk of violence remained significant after adjustment for the effects of known and unknown/unmeasured confounders. These findings support the hypothesis that heavy alcohol use is causal for violence. The novel proxy outcome method enabled the adjustment for the effects of unknown/unmeasured confounders and is a useful tool for improving the reliability of estimated effect sizes in observational research.

\section{Conflict of Interests}

The authors declare that there is no conflict of interests regarding the publication of this paper.

\section{Acknowledgment}

This work was supported by the Australian Government Department of Health and Ageing under the National Drug Strategy's funding of the National Drug Research Institute.

\section{References}

[1] M. L. Exum, "Alcohol and aggression: an integration of findings from experimental studies," Journal of Criminal Justice, vol. 34, no. 2, pp. 131-145, 2006.

[2] H. M. Foran and K. D. O'Leary, "Alcohol and intimate partner violence: a meta-analytic review," Clinical Psychology Review, vol. 28, no. 7, pp. 1222-1234, 2008.

[3] T. A. Ito, N. Miller, and V. E. Pollock, "Alcohol and aggression: a meta-analysis on the moderating effects of inhibitory cues, triggering events, and self-focused attention," Psychological Bulletin, vol. 120, pp. 60-82, 1996.

[4] B. Subra, D. Muller, L. Bègue, B. J. Bushman, and F. Delmas, "Automatic effects of alcohol and aggressive cues on aggressive thoughts and behaviors," Personality and Social Psychology Bulletin, vol. 36, no. 8, pp. 1052-1057, 2010.

[5] S. L. Brown, S. Lipka, S. M. Coyne, P. Qualter, A. Barlow, and P. Taylor, "Implicit alcohol-aggression scripts and alcohol-related aggression on a laboratory task in 11- to 14-year-old adolescents," Aggressive Behavior, vol. 37, no. 5, pp. 430-439, 2011.

[6] P. R. Giancola and D. J. Parrott, "Further evidence for the validity of the Taylor Aggression Paradigm," Aggressive Behavior, vol. 34, no. 2, pp. 214-229, 2008.

[7] C. N. DeWall, R. F. Baumeister, T. F. Stillman, and M. T. Gailliot, "Violence restrained: effects of self-regulation and its depletion on aggression," Journal of Experimental Social Psychology, vol. 43, no. 1, pp. 62-76, 2007.

[8] U. Haggård-Grann, J. Hallqvist, N. Långström, and J. Möller, "The role of alcohol and drugs in triggering criminal violence: a case-crossover study," Addiction, vol. 101, no. 1, pp. 100-108, 2006.

[9] W. Liang and T. Chikritzhs, "Revealing the link between licensed outlets and violence: counting venues versus measuring alcohol availability," Drug and Alcohol Review, vol. 30, no. 5, pp. 524-535, 2011.

[10] R. Caetano, C. McGrath, S. Ramisetty-Mikler, and C. A. Field, "Drinking, alcohol problems and the five-year recurrence and incidence of male to female and female to male partner violence," Alcoholism: Clinical and Experimental Research, vol. 29, no. 1, pp. 98-106, 2005.

[11] T. Norström and H. Pape, "Alcohol, suppressed anger and violence," Addiction, vol. 105, no. 9, pp. 1580-1586, 2010.

[12] K. Graham, P. West, and S. Wells, "Evaluating theories of alcohol-related aggression using observations of young adults in bars," Addiction, vol. 95, no. 6, pp. 847-863, 2000.

[13] S. Fazel, N. Långström, A. Hjern, M. Grann, and P. Lichtenstein, "Schizophrenia, substance abuse, and violent crime," Journal of the American Medical Association, vol. 301, no. 19, pp. 20162023, 2009.

[14] M. A. Straus and G. K. Kantor, "Corporal punishment of adolescents by parents: a risk factor in the epidemiology of depression, suicide, alcohol abuse, child abuse, and wife beating," Adolescence, vol. 29, no. 115, pp. 543-561, 1994.

[15] C. S. Widom and H. R. White, "Problem behaviours in abused and neglected children grown up: prevalence and cooccurrence of substance abuse, crime and violence," Criminal Behaviour and Mental Health, vol. 7, no. 4, pp. 287-310, 1997.

[16] D. Gil-González, C. Vives-Cases, C. Álvarez-Dardet, and J. Latour-Pérez, "Alcohol and intimate partner violence: do we have enough information to act?" The European Journal of Public Health, vol. 16, no. 3, pp. 278-284, 2006. 
[17] W. Liang, Y. Zhao, and A. H. Lee, "A proxy outcome approach for causal effect in observational studies: a simulation study," BioMed Research International, vol. 2014, Article ID 872435, 8 pages, 2014.

[18] W. Liang and T. Chikritzhs, "Observational research on alcohol use and chronic disease outcome: New approaches to counter biases," The Scientific World Journal, vol. 2013, Article ID 860915, 14 pages, 2013.

[19] E. Tchetgen Tchetgen, "The control outcome calibration approach for causal inference with unobserved confounding," American Journal of Epidemiology, vol. 179, no. 5, pp. 633-640, 2014.

[20] W. Liang and T. Chikritzhs, "Alcohol consumption and health status of family members: health impacts without ingestion," Internal Medicine Journal, vol. 43, no. 9, pp. 1012-1016, 2013.

[21] F. Jacobi, H.-U. Wittchen, C. Hölting et al., "Prevalence, comorbidity and correlates of mental disorders in the general population: results from the German Health Interview and Examination Survey (GHS)," Psychological Medicine, vol. 34, no. 4, pp. 597-611, 2004.

[22] Y.-F. Chan, M. L. Dennis, and R. R. Funk, "Prevalence and comorbidity of major internalizing and externalizing problems among adolescents and adults presenting to substance abuse treatment," Journal of Substance Abuse Treatment, vol. 34, no. 1, pp. 14-24, 2008.

[23] M. Teesson, W. Hall, T. Slade et al., "Prevalence and correlates of DSM-IV alcohol abuse and dependence in Australia: findings of the 2007 National Survey of Mental Health and Wellbeing," Addiction, vol. 105, no. 12, pp. 2085-2094, 2010.

[24] W. Liang and T. N. Chikritzhs, "Does light alcohol consumption during pregnancy improve offspring's cognitive development?" Medical Hypotheses, vol. 78, no. 1, pp. 69-70, 2012.

[25] W. Liang and T. Chikritzhs, "Alcohol consumption and health status of family members: Health impacts without ingestion," Internal Medicine Journal, vol. 43, no. 9, pp. 1012-1016, 2013.

[26] E. Petridou, X. Zavitsanos, N. Dessypris et al., "Adolescents in high-risk trajectory: clustering of risky behavior and the origins of socioeconomic health differentials," Preventive Medicine, vol. 26, no. 2, pp. 215-219, 1997.

[27] J. W. Lynch, G. A. Kaplan, and J. T. Salonen, "Why do poor people behave poorly? Variation in adult health behaviours and psychosocial characteristics by stages of the socioeconomic lifecourse," Social Science \& Medicine, vol. 44, no. 6, pp. 809-819, 1997.

[28] A. Rozanski, J. A. Blumenthal, K. W. Davidson, P. G. Saab, and L. Kubzansky, "The epidemiology, pathophysiology, and management of psychosocial risk factors in cardiac practice: the emerging field of behavioral cardiology," Journal of the American College of Cardiology, vol. 45, no. 5, pp. 637-651, 2005.

[29] K.-J. Suzuki, S. Nakaji, S. Tokunaga, T. Umeda, and K. Sugawara, "Confounding by dietary factors in case-control studies on the efficacy of cancer screening in Japan," European Journal of Epidemiology, vol. 20, no. 1, pp. 73-78, 2005.

[30] R. H. H. Groenwold, A. W. Hoes, and E. Hak, "Confounding in publications of observational intervention studies," European Journal of Epidemiology, vol. 22, no. 7, pp. 413-415, 2007.

[31] P. Lagiou, H.-O. Adami, and D. Trichopoulos, "Causality in cancer epidemiology," European Journal of Epidemiology, vol. 20, no. 7, pp. 565-574, 2005.

[32] M. V. Holmes, C. E. Dale, L. Zuccolo et al., "Association between alcohol and cardiovascular disease: mendelian randomisation analysis based on individual participant data," British Medical Journal, vol. 349, Article ID g4164, 2014.

[33] M. Zuckerman and D. M. Kuhlman, "Personality and risktaking: common biosocial factors," Journal of Personality, vol. 68, no. 6, pp. 999-1029, 2000.

[34] R. Loeber, "Development and risk factors of juvenile antisocial behavior and delinquency," Clinical Psychology Review, vol. 10, no. 1, pp. 1-41, 1990.

[35] G. Laviola, S. Macrì, S. Morley-Fletcher, and W. Adriani, "Risktaking behavior in adolescent mice: psychobiological determinants and early epigenetic influence," Neuroscience \& Biobehavioral Reviews, vol. 27, no. 1-2, pp. 19-31, 2003.

[36] F. K. del Boca and J. Darkes, "The validity of self-reports of alcohol consumption: state of the science and challenges for research," Addiction, vol. 98, no. 2, pp. 1-12, 2003.

[37] Department of Health and Human Services, National Survey on Drug Use and Health, 2011, United States Department of Health and Human Services, Substance Abuse and Mental Health Services Administration, Center for Behavioral Health Statistics and Quality, Ann Arbor, Mich, USA, 2012.

[38] Department of Health and Human Services, National Survey on Drug Use and Health, 2010, United States Department of Health and Human Services, Substance Abuse and Mental Health Services Administration, Center for Behavioral Health Statistics and Quality, 2012.

[39] Department of Health and Human Services, National Survey on Drug Use and Health, 2009, United States Department of Health and Human Services, Substance Abuse and Mental Health Services Administration, Center for Behavioral Health Statistics and Quality, 2012.

[40] A. M. M. van Erp and K. A. Miczek, "Increased aggression after ethanol self-administration in male resident rats," Psychopharmacology, vol. 131, no. 3, pp. 287-295, 1997.

[41] J. Dee Higley, "Individual differences in alcohol-induced aggression: A nonhuman-primate model," Alcohol Research and Health, vol. 25, no. 1, pp. 12-19, 2001.

[42] A. J. Heinz, A. Beck, A. Meyer-Lindenberg, P. Sterzer, and A. Heinz, "Cognitive and neurobiological mechanisms of alcoholrelated aggression," Nature Reviews Neuroscience, vol. 12, no. 7, pp. 400-413, 2011.

[43] P. R. Giancola, D. A. Saucier, and N. L. Gussler-Burkhardt, "The effects of affective, behavioral, and cognitive components of trait anger on the alcohol-aggression relation," Alcoholism: Clinical and Experimental Research, vol. 27, no. 12, pp. 1944-1954, 2003.

[44] P. R. Giancola, "Executive functioning: a conceptual framework for alcohol-related aggression," Experimental and Clinical Psychopharmacology, vol. 8, no. 4, pp. 576-597, 2000.

[45] P. R. Giancola, "The influence of trait anger on the alcoholaggression relation in men and women," Alcoholism: Clinical \& Experimental Research, vol. 26, no. 9, pp. 1350-1358, 2002. 


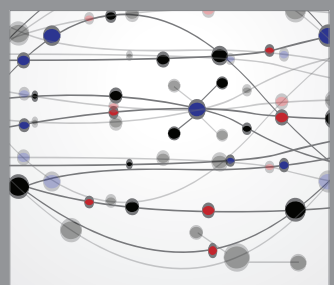

The Scientific World Journal
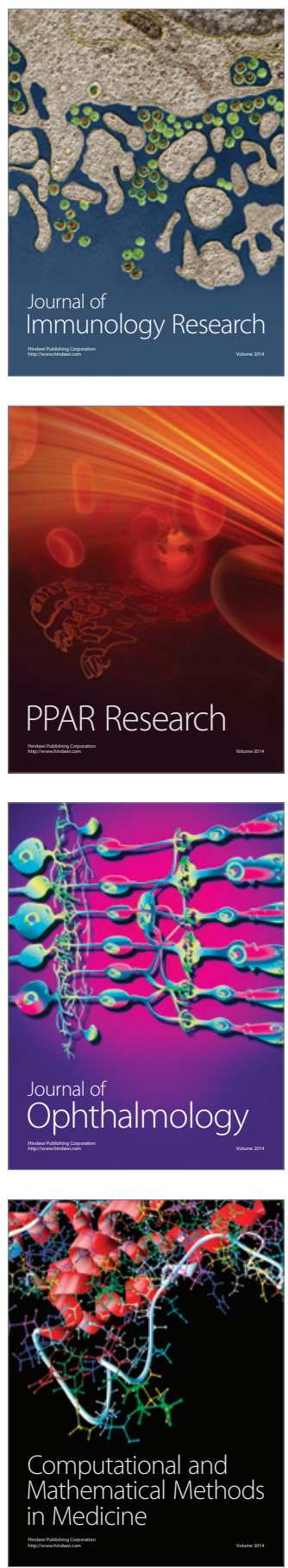

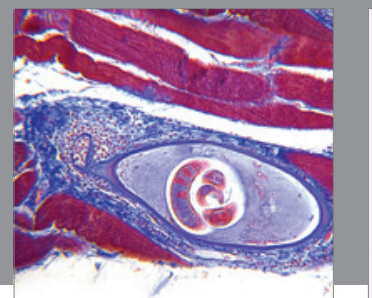

Gastroenterology

Research and Practice
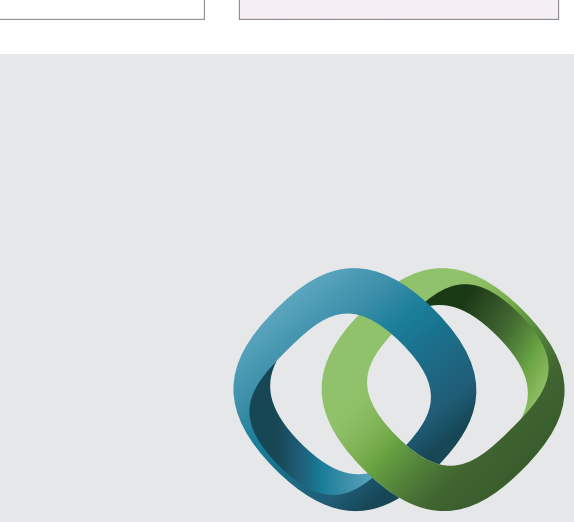

\section{Hindawi}

Submit your manuscripts at

http://www.hindawi.com
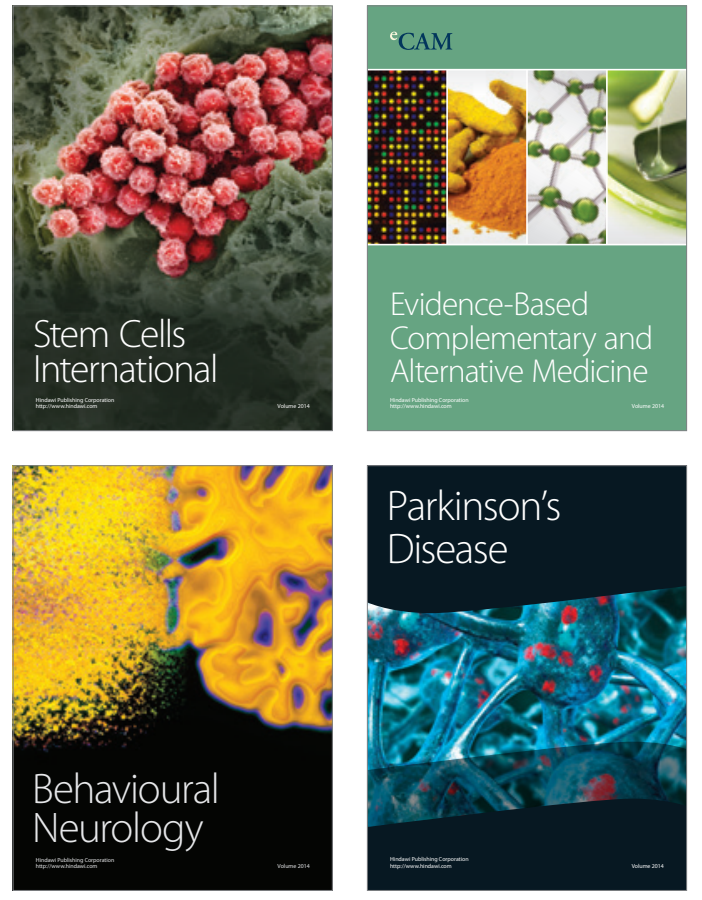
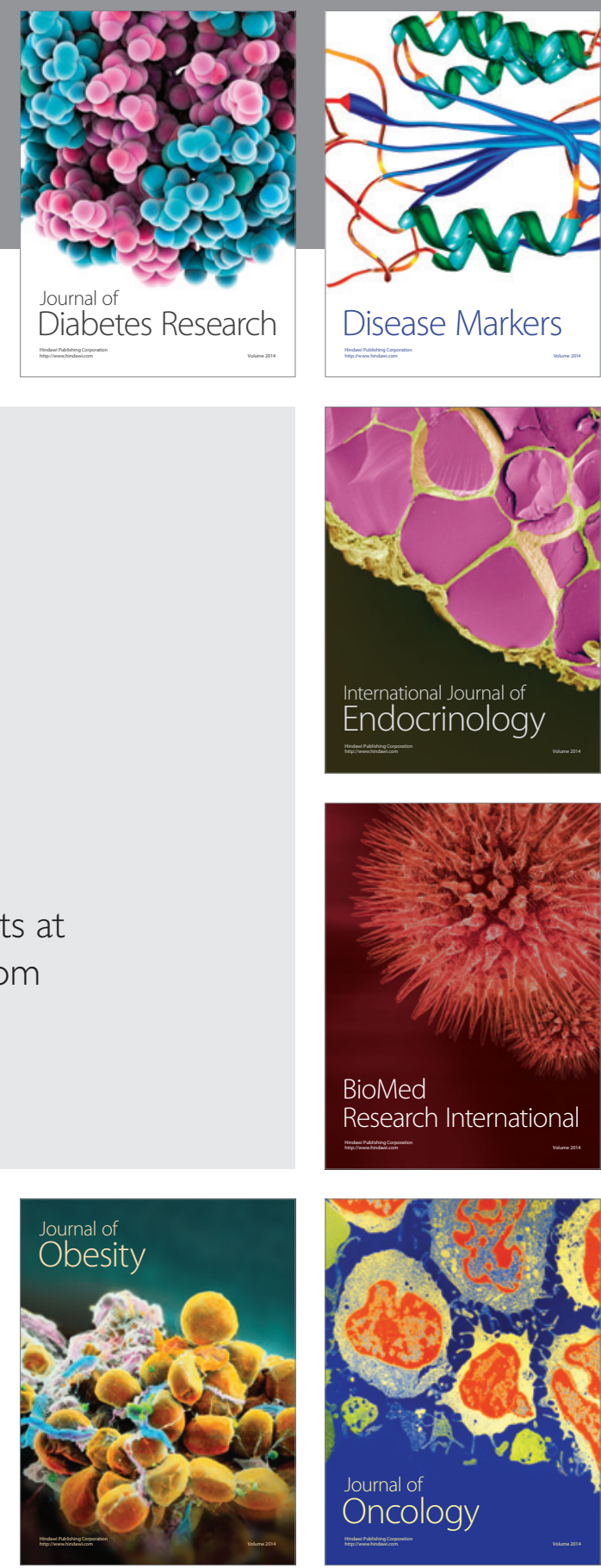

Disease Markers
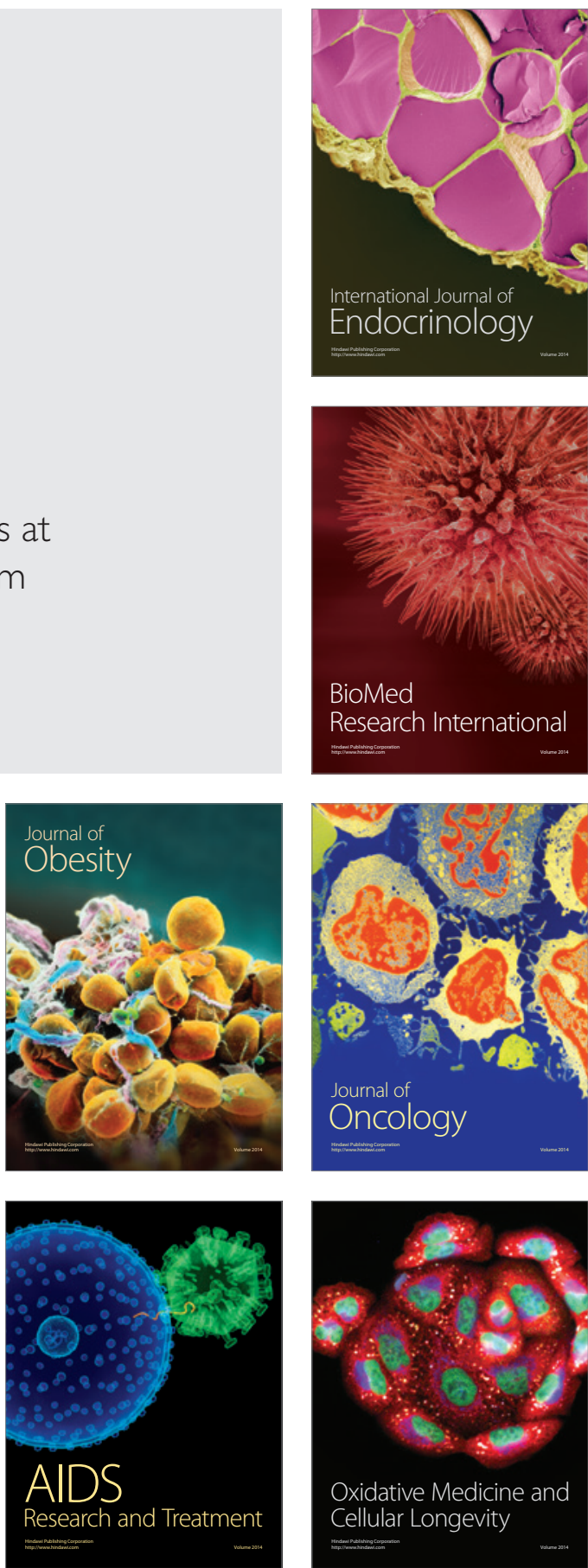